CLINICAL STUDY

\title{
Preserved GLP-1 and exaggerated GIP secretion in type 2 diabetes and relationships with triglycerides and ALT
}

\author{
Marjan Alssema ${ }^{1,2}$, Josina M Rijkelijkhuizen ${ }^{1}$, Jens J Holst ${ }^{3}$, Tom Teerlink ${ }^{4}$, Peter G Scheffer ${ }^{4}$, \\ Elisabeth M W Eekhoff ${ }^{5}$, Amalia Gastaldelli ${ }^{6}$, Andrea Mari ${ }^{7}$, Leen M 't Hart ${ }^{8}$, Giel Nijpels ${ }^{9}$ and Jacqueline M Dekker ${ }^{1}$ \\ ${ }^{1}$ Department of Epidemiology and Biostatistics and the EMGO Institute for Health and Care Research, VU University Medical Center, Amsterdam, \\ The Netherlands, ${ }^{2}$ Unilever Research and Development, Olivier van Noortlaan 120, 3133 AT Vlaardingen, The Netherlands, ${ }^{3}$ Department of Biomedical \\ Sciences, The Panum Institute, The NovoNordisk Foundation Center for Basic Metabolic Research, University of Copenhagen, Copenhagen, Denmark, \\ Departments of ${ }^{4}$ Clinical Chemistry and ${ }^{5}$ Endocrinology, VU University Medical Center, Amsterdam. The Netherlands, ${ }^{6}$ Institute of Clinical Physiology, \\ National Research Council, Pisa, Italy, ${ }^{7}$ Institute of Biomedical Engineering, National Research Council, Padua, Italy, ${ }^{8}$ Department of Molecular Cell \\ Biology, Leiden University Medical Center, Leiden, The Netherlands and ${ }^{9}$ Department of General Practice and the EMGO Institute for Health and Care \\ Research, VU University Medical Center, Amsterdam, The Netherlands
}

(Correspondence should be addressed to M Alssema; Email: marjan.alssema@unilever.com)

\begin{abstract}
Objective: To i) compare incretin responses to oral glucose and mixed meal of diabetic patients with the normoglycaemic population and ii) to investigate whether incretin responses are associated with hypertriglyceridaemia and alanine aminotransferase (ALT) as liver fat marker.

Design: A population-based study.

Methods: A total of 163 persons with normal glucose metabolism (NGM), 20 with intermediate hyperglycaemia and 20 with type 2 diabetes aged 40-65 years participated. Participants received a mixed meal and oral glucose load on separate occasions. Glucagon-like peptide 1 (GLP-1), glucosedependent insulinotropic polypeptide (GIP) and glucagon profiles were analysed as total area under the curve (tAUC) and incremental area under the curve.

Results: In diabetic patients compared with persons with NGM, we found increased GLP-1 secretion (tAUC per hour) following oral glucose (23.2 pmol/l (95\% CI 17.7-28.7) vs 18.0 (95\% CI 16.9-19.1), $P<0.05)$ but not after the mixed meal. GIP secretion among diabetic patients was increased on both occasions (82.9 pmol/l (55.9-109.8) vs 47.1 (43.8-50.4) for oral glucose and 130.6 (92.5-168.7) vs 83.2 (77.5-88.9) for mixed meal, both $P<0.05$ ). After oral glucose, GLP-1 (tAUC per hour) was inversely related to fasting triglycerides. GIP (tAUC per hour) was positively related to fasting and postprandial triglycerides. Higher fasting GIP levels were related to higher fasting and postprandial triglyceride levels and ALT.

Conclusion: This study confirms that in type 2 diabetes, GLP-1 secretion is generally preserved and that GIP secretion is exaggerated. The mechanism underlying the divergent associations of GLP-1 and GIP metabolism with fat metabolism and liver fat accumulation warrants further study.
\end{abstract}

European Journal of Endocrinology 169 421-430

\section{Introduction}

The incretin hormones glucagon-like peptide 1 (GLP-1) and glucose-dependent insulinotropic polypeptide (GIP) are released from the gut upon nutrient ingestion and are known for their insulin-stimulating effects. Among type 2 diabetic patients, a reduced incretin effect has been described (1). The reduced incretin effect has been attributed to a substantial reduction in insulinotropic effect of GIP $(2,3)$ while the insulinotropic efficacy of GLP-1 is largely preserved (3). Given this preserved insulinotropic efficacy of GLP-1, therapeutic interventions with GLP-1 analogues or dipeptidyl peptidase-4 inhibitors have been proven effective in controlling glucose levels in type 2 diabetic patients (4).
Despite this well-established reduced incretin effect among diabetic patients, whether a defect in incretin secretion exists is still not fully resolved $(5,6)$. Secretion of the incretins GLP-1 and GIP following meal intake or oral glucose has been described in a number of studies and was reviewed by Calanna et al. and Nauck et al. $(5,6)$. These authors concluded that patients with type 2 diabetes, in general, do not exhibit reduced GLP-1 secretion $(5,6)$. Nevertheless, heterogeneity was apparent between studies that used mixed meal (lower GLP-1 among diabetes) and oral glucose load (higher GLP-1). Studies that directly compared GLP-1 responses following oral glucose vs mixed meal are scarce and the available studies did not find an altered GLP-1 response after both interventions among diabetic patients (7). 
GIP responses were found to be reduced (8), increased $(7,9)$, but mostly unchanged in patients with diabetes $(10,11,12,13)$. Possible explanations for these inconclusive findings on incretin responses among diabetic patients may relate to the assay used, the test meal, participant characteristics and probably sample size. A large study in a representative study population assessing incretin responses following meal and oral glucose would fill this gap of knowledge.

Clinical studies have demonstrated benefits of GLP-1-based therapies that go beyond the effects of incretins in insulin and glucose metabolism. These include direct cardiovascular effects (14) and effects on the liver (15). Dyslipidemia is a well-known feature of type 2 diabetic patients (16) and an acknowledged risk factor for cardiovascular disease (17). The role of incretins in lipid metabolism is of specific interest as experimental studies have demonstrated differential effects of GLP-1 and GIP on lipid metabolism. Infusion of GLP-1 analogues abolished the rise in postprandial triglycerides after a mixed meal in healthy individuals (18). In addition, among patients with type 2 diabetes, treatment with a GLP-1 analogue or GLP-1 agonist has been demonstrated to improve blood lipid levels and cardiovascular disease risk $(19,20)$. Experimental studies in obesity-prone mice have shown that administration of a GLP-1 receptor agonist prevents weight gain and development of a fatty liver (21). In contrast, GIP receptors are thought to promote fat deposition and fatty acid synthesis in adipose tissue (22). Administration of a GIP receptor antagonist reverses obesity and insulin resistance in high-fat-fed mice (23). In humans, the beneficial effects of bariatric surgery in curing diabetes among obese persons were accompanied by a rapid decrease in GIP, suggesting that lowering GIP levels may play a role in the metabolic effects of such a surgery (24).

The aim of this study was twofold; first, to perform a population-based study to assess GLP-1 and GIP responses to oral glucose and a mixed meal among a study group representative for the general population. Secondly, we aimed to investigate whether GLP-1 and GIP responses are associated with markers of abnormal lipid metabolism.

\section{Subjects and methods}

\section{Study procedure}

The study population consisted of 194 persons who were randomly invited from the general population aged 40-65 years in Hoorn, The Netherlands. Another 14 patients with type 2 diabetes (not using insulin) from the Regional Diabetes Care System additionally participated to increase the number of type 2 diabetic patients. Details of the inclusion criteria were described earlier (25). After exclusion of three persons with missing data on incretin and/or glucagon response following meal, one person with uninterpretable oral glucose tolerance test (OGTT) and one person with type 1 diabetes, the number of persons for the present analysis was 203 and consisted of 20 persons with type 2 diabetes, 20 with intermediate hyperglycaemia $(\mathrm{IH})$ (being isolated impaired fasting glucose, $n=14$; isolated impaired glucose tolerance, $n=3$; or both impaired fasting glucose and impaired glucose tolerance, $n=3$ ) and 163 with normal glucose metabolism (NGM) (26). All participants signed informed consent with respect to the study and the medical ethics committee of the VU University Medical Centre approved the study.

Participants underwent a 2-h 75 g OGTT and a 4-h standardized mixed meal test (MMT) on separate occasions in random order. Tests were performed after a 10-h overnight fast, and apart from small amounts of water, participants refrained from oral glucose-lowering medication (if applicable), food, drinks and physical activity during the test. Blood samples were drawn from the antecubital vein in the fasting state and at predefined time-points during the test. Blood pressure (Collin Press-mate BP-8800, Colin, Komaki-City, Japan), weight, height, and waist and hip circumference were measured prior to the test.

The mixed meal consisted of two croissants, butter, Gouda cheese, full-fat milk and yogurt drink with soluble carbohydrates (maltose). The nutrient content was $3487 \mathrm{~kJ}, 36$ energy\% carbohydrates, 52 energy\% fat and 12 energy $\%$ proteins.

\section{Laboratory analyses}

Total GLP-1 levels were determined using RIA (antiserum 89390) against standards of synthetic GLP-1 7-36 amide. The assay measures the sum of intact GLP-1 and the primary metabolite, GLP-1 9-36 amide as described previously (27). Total GIP was measured using the $\mathrm{COOH}$ terminally directed antiserum R65, which reacts fully with intact human GIP and the $\mathrm{NH}_{2}$ terminally truncated metabolite (28). For both assays, sensitivity was below $1 \mathrm{pmol} / \mathrm{l}$ and intra-assay coefficient of variation below $6 \%$ at $20 \mathrm{pmol} / \mathrm{l}$.

Serum total and HDL-cholesterol levels and triglycerides were measured by enzymatic colorimetric assays (Roche). Alanine aminotransferase (ALT) was measured by the IFCC method (Roche Diagnostics). Plasma glucose levels were determined by a glucose hexokinase method (Gluco-quant, Roche Diagnostics). A1c was determined using reversed-phase cation exchange chromatography (HA 8160 analyzer, Menarini, Florence, Italy) accompanied by the use of a method to standardize HbAlc across laboratories (DCCT-standardization). Serum C-peptide and insulin levels were determined by immunometric assays (ACS Centaur, Bayer Diagnostics). Glucagon levels were determined in EDTA samples by RIA, after extraction (Linco Research, St Louis, MO, USA) with inter- and intra-assay coefficients of variation of $8 \%$ and lower limit of quantitation of $2.3 \mathrm{pmol} / \mathrm{l}$. 


\section{Statistical analyses}

Differences in characteristics between persons with type 2 diabetes and $\mathrm{IH}$ when compared with those with NGM were analysed by one-way ANOVA. In case of significant F-test, comparative testing was done against persons with NGM with least significant difference post hoc test. Differences in percentages were tested by $\chi^{2}$. Skewed variables were ln-transformed before testing.

Total area under the curve (tAUC) and incremental area under the curve (iAUC) for incretin and glucagon responses were calculated as time-corrected area under the curve (AUC per hour in pmol/l). Differences in incretin and glucagon tAUC and iAUC between groups were analysed by one-way ANOVA. As differences in obesity may account for the different responses among diabetic patients, incretin tAUC in diabetic patients was also compared with that in non-diabetic patients stratified by BMI. Mean BMI in the non-diabetic group with BMI $\geq 30 \mathrm{~kg} / \mathrm{m}^{2}$ was $32.9 \mathrm{~kg} / \mathrm{m}^{2}$ and as such was comparable to the BMI of the diabetic patients $\left(33.1 \mathrm{~kg} / \mathrm{m}^{2}\right)$.

Insulin sensitivity was estimated by calculation of the oral glucose insulin sensitivity index (OGIS), which was calculated from $t=0,90$ and 120 min upon OGTT (29). OGIS is an estimate of the glucose clearance during a hyperinsulinaemic-euglycaemic glucose clamp and as such expressed in $\mathrm{ml} / \mathrm{min}$ per $\mathrm{m}^{2}$ body surface area (29).

After the calculation of overall AUC for hormone responses, we aimed to investigate the postprandial patterns of these responses. Therefore, time-dependent GLP-1, GIP and glucagon profiles were analysed by linear mixed models. Linear mixed models use all available data over time and account for correlations between repeated measurements (30). The first models included the variables test occasion (being oral glucose or mixed meal), time, and glucose tolerance state and estimated regression coefficients with 95\% CIs. The coefficient for test occasion estimated the effect of oral glucose in comparison with mixed meal on incretin and glucagon responses. Subsequently, we used a model that included glucose tolerance state, time and interactions between glucose tolerance state and time for both test occasions separately. A significant interaction between time and glucose tolerance state is interpreted as a stronger rate of change over time attributable to glucose tolerance state. In these analyses, adjustments were made for age and sex.

Further analyses on variables potentially explaining the GLP-1, GIP and glucagon responses to the meal were assessed in a univariate linear regression model with the tAUC of these responses as an outcome variable. Linear regression analysis was performed with fasting and tAUC of GLP-1 and GIP in relation to (postprandial) triglycerides and ALT. For these analyses, 21 persons who used lipid-lowering medication (11 of them were NGM, three IH and seven diabetic patients) were excluded. As potential confounding factors, we added age, sex and glucose tolerance state to the model. Subsequently, OGIS and glucagon responses were added to the model as potential explanatory variables of the relationship between incretins and triglycerides or ALT. Although no medication was used on the test day, metformin may have impacted on the GLP-1 response as it has been suggested to act as a GLP-1 enhancer (31). Therefore, we performed a sensitivity analysis by excluding patients who were on metformin. In all analyses, a $P$ value $<0.05$ was considered statistically significant except for interaction terms where we used $P<0.10$ as statistically significant.

\section{Results}

\section{Characteristics of study participants}

Type 2 diabetic patients participating in this study had a median diabetes duration of 3.5 years; this group includes three patients who were newly diagnosed at the first study visit. Mean HbAlc among these diabetic patients was $7.1 \%(54.1 \mathrm{mmol} / \mathrm{mol})$ (Table 1$)$.

Patients with type 2 diabetes and persons with $\mathrm{IH}$ were significantly more overweight (BMI and waist circumference), had higher systolic blood pressure and triglyceride levels, and lower HDL-cholesterol levels than those with NGM ( $P<0.05$ for all comparisons). Patients with type 2 diabetes used more medication both for blood pressure and lipids $(P<0.05)$. Further, persons with $\mathrm{IH}$ and type 2 diabetes had higher levels of ALT $(P<0.05)$. When compared with persons with NGM, persons with diabetes had higher mean levels of glucagon, GLP-1 and GIP in the fasting state $(P<0.05$, Table 1$)$. Persons with $\mathrm{IH}$ had higher fasting GLP-1 $(P<0.05)$ but not GIP $(P=0.29)$ or glucagon $(P=0.07$, Table 1$)$.

\section{Responses following mixed meal and oral glucose}

Glucose, insulin and triglyceride responses following oral glucose and mixed meal are presented in Fig. 1. GLP-1, GIP and glucagon responses are presented in Fig. 2. Among the total study population, the OGTT elicited a higher GLP-1 response $(P<0.05)$, a nonsignificantly lower GIP response $(P=0.58)$ and a lower glucagon response $(P<0.05)$ than the mixed meal (assessed by linear mixed models, Fig. 2).

The response in GLP-1 following oral glucose (t120) but especially following mixed meal (t15 and t90, t120, t180 and $\mathrm{t} 240$ ) was lower among patients with type 2 diabetes $(P$ value interaction for time $\times$ type 2 diabetes state $<0.10$, Fig. 2D). GLP-1 tAUC per hour among diabetic patients was similar after the mixed meal $(P=0.32)$ and higher after oral glucose $(P<0.01)$, in comparison with normoglycaemic persons (Fig. 3). Despite higher tAUC after the mixed meal, the iAUC 
Table 1 Characteristics of study participants. Values represent means (s.D.) or medians (interquartile range) in case of skewed distribution.

\begin{tabular}{|c|c|c|c|}
\hline & NGM & IH & T2DM \\
\hline$n$ & 163 & 20 & 20 \\
\hline Age (years) & $53.1(6.8)$ & $56.6(5.3)$ & $53.3(6.7)$ \\
\hline Sex (\% male) & 47.2 & 60.0 & 60.0 \\
\hline BMI $\left(\mathrm{kg} / \mathrm{m}^{2}\right)$ & $26.7(3.7)$ & $28.5(3.7)$ & $33.1(7.3)^{\star}$ \\
\hline Waist circumference $(\mathrm{cm})$ & $92.7(10.6)$ & $102.7(11.0)^{*}$ & $113.8(17.2)^{*}$ \\
\hline Use of anti-hypertensives (\%) & 15.3 & 25.0 & $60.0^{*}$ \\
\hline Systolic blood pressure (mmHg) & $134(14)$ & $143(22)^{*}$ & $140(16)^{\star}$ \\
\hline Diastolic blood pressure $(\mathrm{mmHg})$ & $76(9)$ & $80(10)$ & $78(9)$ \\
\hline Use of lipid-lowering medication (\%) & 6.7 & 15.8 & $35.0^{*}$ \\
\hline Total cholesterol $(\mathrm{mmol} / \mathrm{l})$ & $5.1(1.0)$ & $5.5(1.0)$ & $4.6(0.9)$ \\
\hline HDL-cholesterol (mmol/l) & $1.42(0.38)$ & $1.21(0.24)^{\star}$ & $1.12(0.42)^{\star}$ \\
\hline Fasting triglycerides $(\mathrm{mmol} / \mathrm{l})$ & $1.2(0.9-1.6)$ & $1.7(1.3-2.3)^{\star}$ & $1.8(1.4-2.3)^{\star}$ \\
\hline $\mathrm{ALT}(\mathrm{U} / \mathrm{I})$ & $10(7-14)$ & $15(10-21)^{*}$ & $19(14-24)^{*}$ \\
\hline OGIS $\left(\mathrm{ml} / \mathrm{min}\right.$ per $\left.\mathrm{m}^{2}\right)$ & $424(57)$ & $326(49)^{*}$ & $306(43)^{\star}$ \\
\hline Fasting glucagon (pmol/l) & $9.7(2.4)$ & $10.9(3.5)$ & $13.9(4.7)^{\star}$ \\
\hline Fasting GLP-1 (pmol/l) & $10.8(4.0)$ & $13.9(6.8)^{*}$ & $16.7(6.0)^{\star}$ \\
\hline Fasting GIP (pmol/l) & $7.0(5.6)$ & $8.6(5.9)$ & $14.1(9.5)^{\star}$ \\
\hline $\mathrm{HbA} 1 \mathrm{c}(\% / \mathrm{mmol}$ per mol) & - & - & $7.1(1.4) / 54.1(15.2)$ \\
\hline Diabetes duration (years) & - & - & $3.2(1.2-5.4)$ \\
\hline $\begin{array}{l}\text { Diabetes treatment (diet only/metformin } \\
\text { only/metformin and SU/SU only) }\end{array}$ & - & - & $n=5 / n=9 / n=5 / n=1$ \\
\hline
\end{tabular}

*Significant difference $(P<0.05)$ by ANOVA (continuous variables) or $\chi^{2}$ test (percentages) against NGM. ALT, alanine aminotransferase; IH, intermediate hyperglycaemia; NGM, normal glucose metabolism; OGIS, oral glucose insulin sensitivity index; T2DM, type 2 diabetes.

per hour of GLP-1 was lower for diabetic patients following mixed meal $(P<0.05)$ but not oral glucose $(P=0.63$, Supplementary Figure 1 , see section on supplementary data given at the end of this article). The GLP-1 response upon mixed meal was similar for metformin and non-metformin users (data not shown). Persons with IH had similar tAUC GLP-1 response to those with NGM both following oral glucose and mixed meal $(P=0.12$ and $P=0.18$ respectively).

The GIP response was more pronounced in diabetic patients at t15, t30, t60 and t90 min after oral glucose and at t30, t60, t90 and t 120 after mixed meal ( $P$ value interaction <0.10). Interestingly, the GIP response was also elevated among persons with IH after oral glucose (t30 and t60) (Fig. 2) and after the mixed meal at t30 t60, t90 and t240 ( $P$ value for interaction $<0.10)$ (Fig. 2). Total and incremental AUC per hour of GIP was significantly higher for diabetic patients following both oral glucose and mixed meal $(P<0.01$ for all comparisons) and for persons with $\mathrm{IH}$ following mixed meal $(P<0.01$ for both tAUC and iAUC), but not after oral glucose $(P=0.08$ and 0.06 for tAUC and iAUC respectively; Fig. 3 and Supplementary Figure 1).

In type 2 diabetic patients, the suppression in glucagon was delayed after oral glucose (t15 and t30, $P$ value interaction $<0.10)$ in comparison with normoglycaemic persons, while the increase in glucagon after mixed meal was more pronounced (t30, $P$ value interaction $<0.10)$. This was followed by stronger suppression later on (t90 and t120 after oral glucose and t120, t180 and t 240 after mixed meal, all $P$ value interaction $<0.10)$. Total AUC per hour glucagon after both oral glucose and mixed meal was higher in diabetic patients $(P<0.01$ for both $)$ and in persons with IH $(P<0.01$ and $P<0.05$ for oral glucose and mixed meal respectively, Fig. 3).

Patients with diabetes had a higher tAUC per hour of GLP-1 after oral glucose and a higher tAUC per hour of GIP when compared with non-diabetic persons with similar BMI (Fig. 4). There were no differences in tAUC per hour of GLP-1 or GIP between subgroups of BMI among non-diabetic individuals (Fig. 4).

\section{Determinants of GLP-1, GIP and glucagon responses}

Univariate associations with GLP-1, GIP and glucagon tAUC per hour to the meal are presented in Table 2 . None of the variables studied were associated with the GLP-1 response. Glucose tolerance state (both IH and diabetes) and the glucagon response were associated with higher GIP response and OGIS was associated with lower GIP response. BMI, waist circumference and glucose tolerance state (both $\mathrm{IH}$ and diabetes) were associated with a higher glucagon response to meal and male gender and OGIS with a lower glucagon response to meal (Table 2).

\section{Associations with triglycerides and ALT}

Results of linear regression analyses with fasting and postprandial triglycerides and ALT as dependent variables are shown in Table 3. Fasting GLP-1 levels were not associated with fasting or postprandial triglycerides or ALT (Table 3). Fasting levels of GIP were associated with 
A

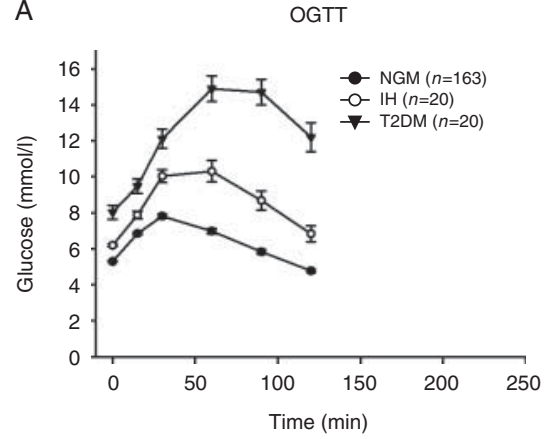

D

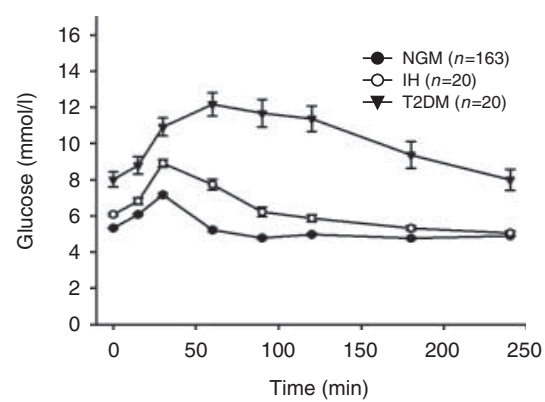

B

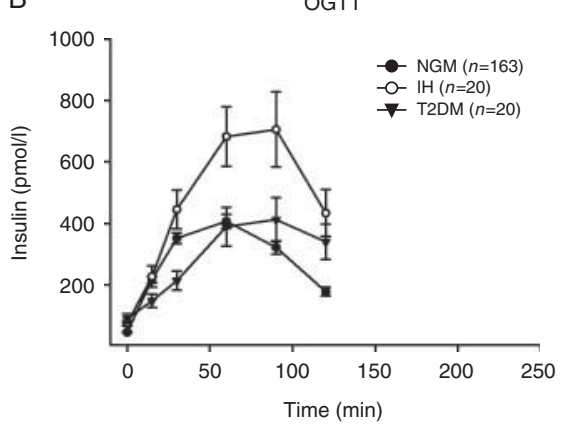

E

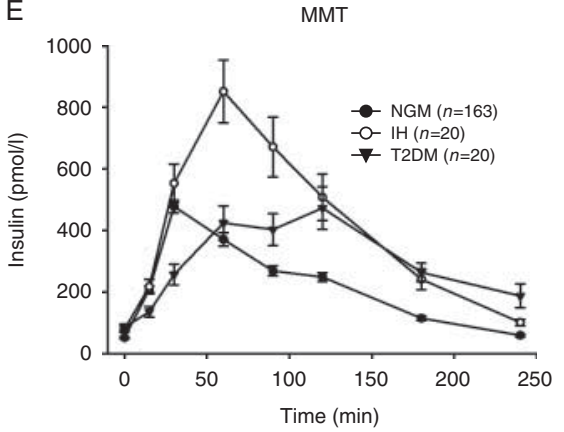

C

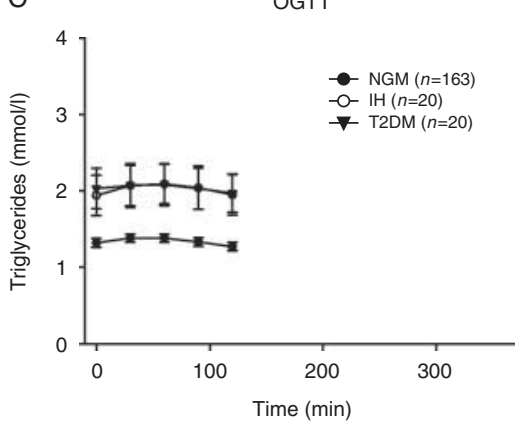

F

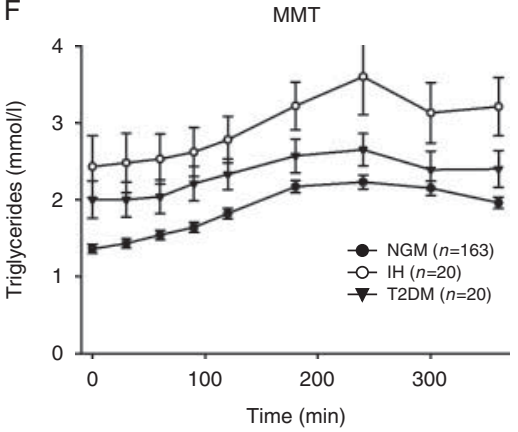

Figure 1 Glucose, insulin and triglyceride responses (mean \pm S.E.M.) to oral glucose tolerance test (OGTT) (A, B, and C) and mixed meal test (MMT) (D, E, and F) among 163 persons with normal glucose metabolism (NGM) (black circles), 20 with intermediate hyperglycaemia $(\mathrm{IH})$ (open circles) and 20 with type 2 diabetes (T2DM) (black triangles).

fasting and postprandial triglycerides and ALT, also after full adjustment for glucose tolerance state, OGIS and fasting glucagon (model 3, Table 3).

GLP-1 tAUC per hour after oral glucose was inversely related to fasting but not postprandial triglycerides in some models (Table 3). GIP-tAUC per hour after oral glucose was positively related to fasting and postprandial triglycerides also after full adjustment (Table 3). The GLP-1 and GIP responses to oral glucose were unrelated to ALT. GLP-1 and GIP-tAUC per hour after mixed meal was not associated with triglycerides or ALT (Table 3).

\section{Discussion}

We found an increased GLP-1 secretion following oral glucose but not after mixed meal, together with an overall increased GIP response among diabetic patients when compared with persons with NGM. After oral glucose, GLP-1 (tAUC per hour) was inversely related to fasting triglycerides, while GIP (tAUC per hour) was positively related to fasting and postprandial triglycerides. Further, higher fasting GIP levels were related to higher fasting and postprandial triglycerides and ALT.

\section{Strengths and limitations of the study}

The size of the study together with the population-based design is strength. The sample size had a number of advantages. First, it enabled us to assess multiple factors associated with incretin responses. Secondly, it allowed linear mixed model analyses to fully explore time effects. Another strength of the study is that we measured oral glucose and mixed meal responses among persons with NGM, IH and type 2 diabetes. As such, the study is more comprehensive than existing studies. A limitation is the cross-sectional nature of the study, not enabling us to study incretin responses along the natural history of type 2 diabetes development. Another limitation is that the subgroup of 20 persons with IH consisted of persons with impaired fasting glucose and/or impaired glucose tolerance that may (32) or may not (33) differ from each other in incretin secretion patterns. Because of limited numbers, we were unable to separate these subgroups in the analysis. However, the majority of persons in this subgroup had impaired fasting glucose, and therefore results can be interpreted as valid for this subgroup.

\section{Glucose tolerance state and other determinants of incretin and glucagon responses}

Although the reduced incretin effect among diabetic patients has been well characterized for some time (1), a potential defect in incretin secretion may only be present in patients with long-standing diabetes $(5,6)$. This study demonstrates higher GLP-1 response (tAUC) after oral glucose among patients with diabetes when compared with persons with NGM, while no altered GLP-1 response after mixed meal is observed. This is in 
A

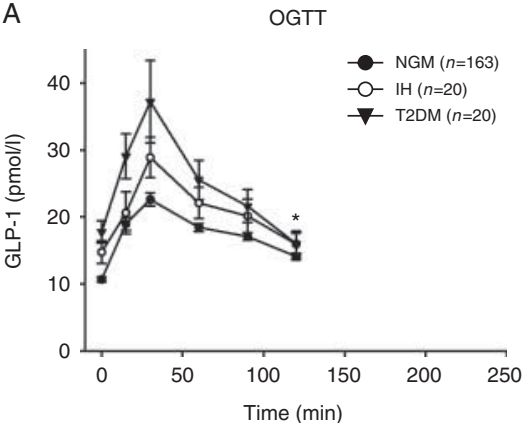

D

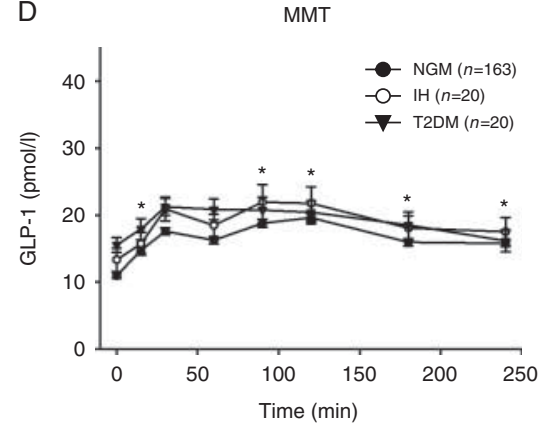

B

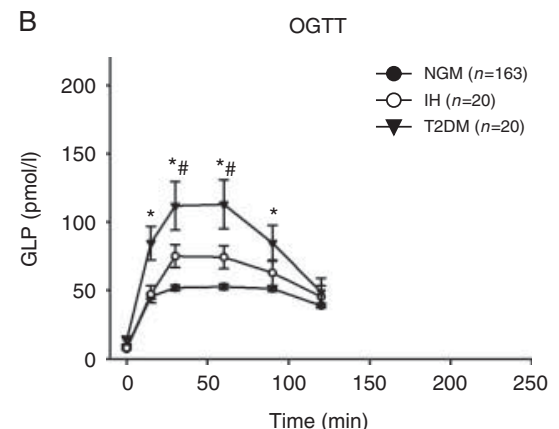

E

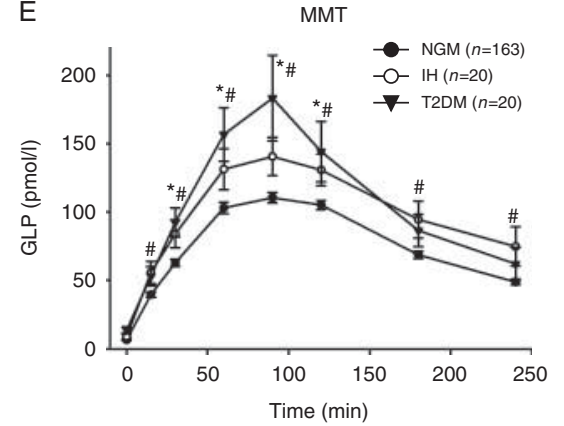

C

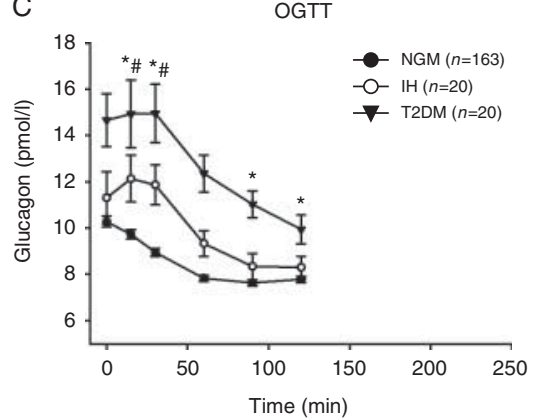

F
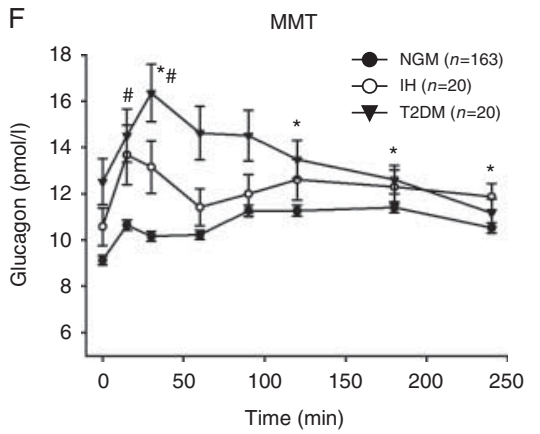

Figure 2 GLP-1, GIP and glucagon responses (mean \pm s.E.M.) to oral glucose tolerance test (OGTT) (A, B, and C) and mixed meal test (MMT) (D, E, and F) among 163 persons with normal glucose metabolism (NGM) (black circles), 20 with intermediate hyperglycaemia (IH) (open circles) and 20 with type 2 diabetes (T2DM) (black triangles). *Significant interaction between time and T2DM in linear mixed models, indicating a significant different change from t0 among T2DM compared with NGM. "Significant interaction between time and IH in linear mixed models, indicating a significant different change from t0 among IH compared with NGM.

line with earlier meta-analyses showing that diabetic state impacts differentially on GLP-1 response to oral glucose and mixed meal $(5,6)$. While the GLP-1 response after oral glucose (tAUC) was increased in diabetic patients, we observed a preserved total GLP-1 response (tAUC) but an almost 50\% diminished iAUC after the mixed meal among diabetic patients. This implies that if a diabetes-related defect in GLP-1 secretion exists, it would be a defect in response to nutrients other than glucose, which has been suggested earlier (34). More complex carbohydrates may play a role here (35). Alternatively, fat is known as a potent stimulus for GLP-1 secretion $(36,37)$ but whether GLP-1 response to fat is different among diabetic patients would be a topic for further study. Another explanation for the higher GLP-1 response after oral glucose vs the solid mixed meal would be an accelerated gastric emptying that has been described for early diabetic patients during a liquid meal $(38,39)$.

In line with earlier studies, GLP-1 response among persons with $\mathrm{IH}$ was unaltered $(7,8,10,40,41)$. This suggests that a defect in GLP-1 secretion is unlikely to precede type 2 diabetes development, which is consistent with earlier findings among first-degree diabetes relatives, and in induced insulin resistance among healthy subjects $(27,42)$.

Next to diabetes, several other factors have been described to influence GLP-1 secretion, i.e. obesity, diabetes duration, rate of gastric emptying, gall bladder kinetics and metformin use (43). We were unable to address them all, but we found no association with obesity, age, gender, OGIS or glucagon response. In addition, BMI-stratified analyses clearly showed no effect of BMI on incretin responses in the present population.

The increased GIP response among persons with diabetes and $\mathrm{IH}$ observed after both oral glucose and mixed meal adds to the existing literature. Earlier studies among diabetic patients mostly report no change in GIP response after a meal or oral glucose $(10,11,12,13)$, a higher response $(7,9,41)$ or a slightly lower response $(8,44)$. Similarly, GIP response among persons with $\mathrm{IH}$ has been reported unaltered $(8,41)$, decreased (40) or increased (7). Obesity has been reported to be associated with higher GIP responses (43), but we did not find a relationship between BMI and GIP meal response. Instead, OGIS was related to lower GIP response. We may speculate that GIP secretion is increased as a compensation for the well-known reduced GIP effect in diabetes (3). Alternatively, the relatively well-controlled diabetes and short diabetes duration of these patients may explain the high GIP response upon oral glucose and mixed meal.

The observation that glucagon was suppressed after oral glucose but increased following mixed meal may relate to the incretin patterns associated with these 

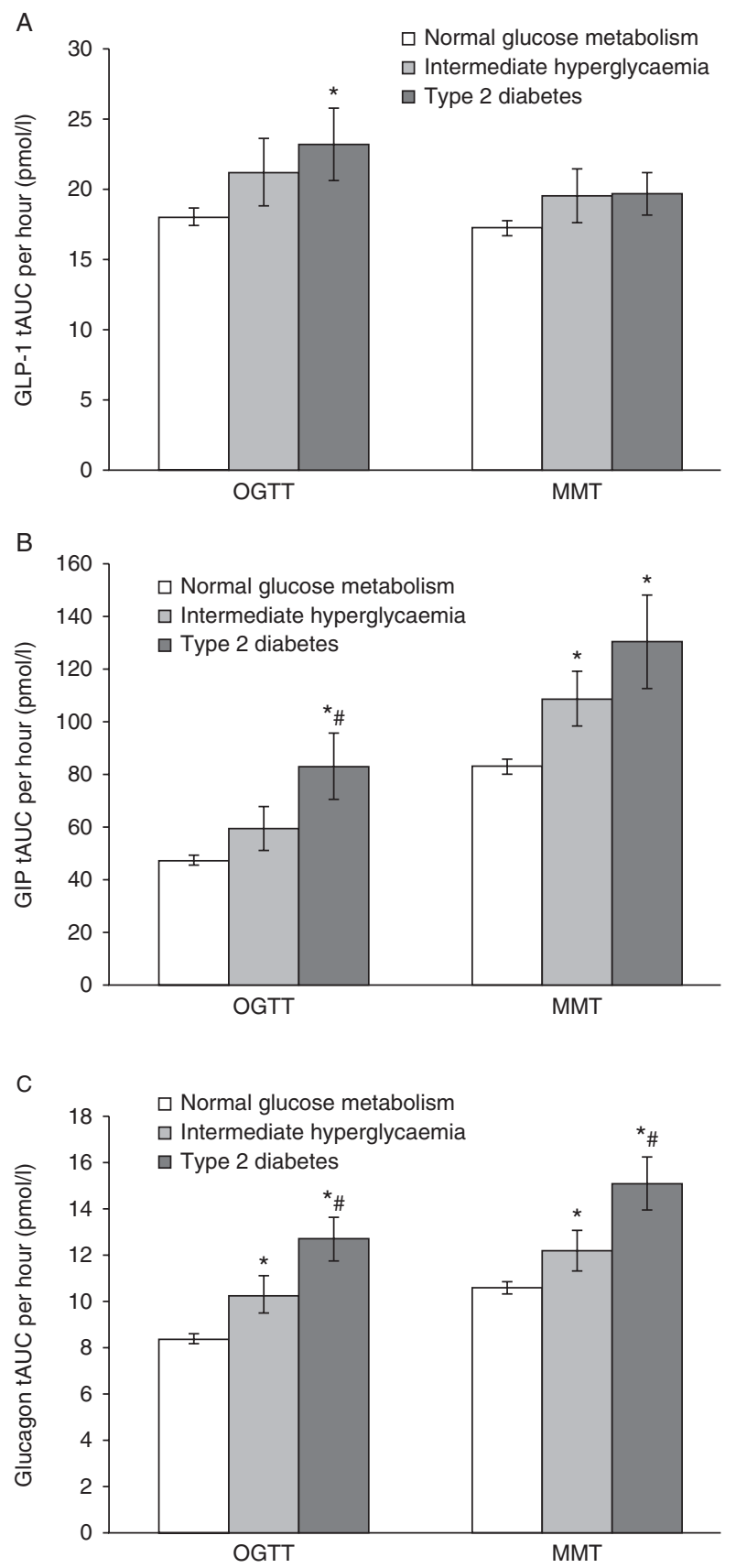

Figure 3 Total area under the curve (tAUC) of GLP-1 (A), GIP (B) and glucagon $(C)$ (mean \pm S.E.M.) following oral glucose tolerance test (OGTT) and mixed meal test (MMT) calculated over the first $2 \mathrm{~h}$ of the test in 163 persons with normal glucose metabolism (NGM), 20 with $\mathrm{IH}$ and 20 with type 2 diabetes. ${ }^{*}$ Significant difference by ANOVA against NGM. \#Significant difference by ANOVA against IH.

tests. GLP-1 is known to suppress, while GIP and also GLP-2 stimulate glucagon secretion (45). The lower GLP-1 and the higher GIP response after the mixed meal when compared with oral glucose may explain the relatively higher glucagon secretion.

\section{Fasting incretins in relation to triglycerides and $A L T$}

The cause of increased fasting GLP-1 and GIP levels in type 2 diabetic patients is unknown so far. Elevated fasting levels of GLP-1 as found among type 2 diabetic patients in this study and in an earlier study may indicate chronic elevated GLP-1 (8). In isolated perfused porcine ileum, a feed-forward mechanism was described where high plasma glucose enhanced fasting GLP-1 (46). We suggest that higher fasting incretin levels may reflect a compensatory mechanism to overcome the loss in islet response, which has been described as an early sign of development of hyperglycaemia (43). Indeed, fasting GLP-1 was already increased among persons with IH (this study) and may therefore develop gradually along the line of hyperglycaemia.

The finding that fasting GIP was related to fasting and postprandial triglycerides and ALT is novel. Fasting GIP was reported to increase upon high-fat feeding for 5 days in healthy individuals and was as such suggested to mediate the increase in insulin secretion that compensated for the increase in hepatic insulin resistance (47). Levels of ALT were not measured in that study, but along with the increase in GIP, an increase in aspartate aminotransferase, another marker of liver fat accumulation, was reported (47). In animal models, long-term administration of a GIP receptor antagonist decreased
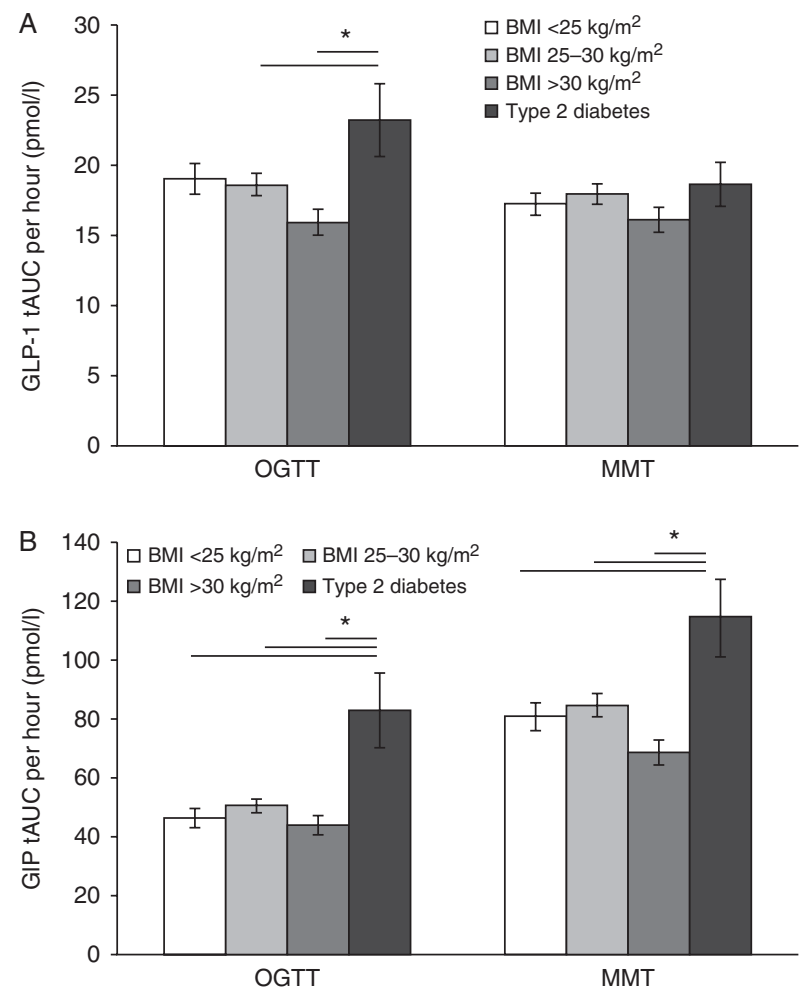

Figure 4 Total AUC of GLP-1 (A) and GIP (B) following oral glucose tolerance test (OGTT) and mixed meal test (MMT) stratified by BMI and type 2 diabetes. *Significant difference by ANOVA. 
Table 2 Univariate associations with GLP-1, GIP and glucagon responses to the meal (tAUC) by univariate regression analysis among the total study population $(n=203)$.

\begin{tabular}{|c|c|c|c|}
\hline & \multicolumn{3}{|c|}{ Regression coefficient $(95 \% \mathrm{Cl})$} \\
\hline & GLP-1-tAUC & GIP-tAUC & Glucagon-tAUC \\
\hline Age (years) & $-0.007(-0.030$ to 0.015$)$ & $0.021(-0.002$ to 0.043$)$ & $0.016(-0.006$ to 0.038$)$ \\
\hline Sex (male) & $0.239(-0.057$ to 0.534$)$ & $0.215(-0.082$ to 0.512$)$ & $-0.526(-0.808 \text { to }-0.244)^{*}$ \\
\hline BMI $\left(\mathrm{kg} / \mathrm{m}^{2}\right)$ & $-0.010(-0.042$ to 0.022$)$ & $-0.002(-0.034$ to 0.030$)$ & $0.038(0.007 \text { to } 0.070)^{*}$ \\
\hline Waist circumference $(\mathrm{cm})$ & $-0.005(-0.016$ to 0.006$)$ & $0.003(-0.008$ to 0.014$)$ & $0.022(0.012 \text { to } 0.032)^{\star}$ \\
\hline \multicolumn{4}{|l|}{ Glucose tolerance state } \\
\hline $\mathrm{IH}$ & $0.330(-0.152$ to 0.811$)$ & $0.706(0.252 \text { to } 1.161)^{\star}$ & $0.482(0.025 \text { to } 0.939)^{*}$ \\
\hline Type 2 diabetes & $0.248(-0.245$ to 0.741$)$ & $0.971(0.517 \text { to } 1.426)^{*}$ & $1.041(0.573 \text { to } 1.509)^{*}$ \\
\hline OGIS $\left(\mathrm{ml} / \mathrm{min}\right.$ per $\left.\mathrm{m}^{2}\right)$ & $0.001(-0.001$ to 0.003$)$ & $-0.003(-0.005 \text { to }-0.000)^{*}$ & $-0.004(-0.006 \text { to }-0.002)^{*}$ \\
\hline Glucagon tAUC per hour (pmol/l) & $-0.036(-0.186$ to 0.113$)$ & $0.200(0.052 \text { to } 0.348)^{*}$ & - \\
\hline
\end{tabular}

OGIS, oral glucose insulin sensitivity index; tAUC, total area under the curve; IH, intermediate hyperglycaemia. Regression coefficient indicates increase in SD tAUC per hour per unit as indicated (years for age, etc.); ${ }^{\star} P<0.05$.

adipose tissue mass and triglyceride deposition in liver and muscle (23). So the notion of GIP adversely related to lipid metabolism and fatty liver is in line with earlier findings, but the mechanisms underlying increased fasting GIP levels warrant further study.

\section{Incretin responses in relation to triglycerides and $A L T$}

The oral glucose responses of GLP-1 and GIP showed opposite directions of association with triglycerides. The inverse relationship between GLP-1 response (tAUC) after oral glucose load and fasting triglycerides is consistent with clinical study results among patients with type 2 diabetes, showing that treatment with a GLP-1 analogue or GLP-1 agonist improves blood lipid profile $(19,20)$. The positive relationship between tAUC GIP after oral glucose and (postprandial) triglycerides adds to findings from animal studies that indicate an adverse role of GIP in lipid metabolism (48).

\section{Implications of the study}

As the MMT reflects habitual hormone patterns more closely than does an oral glucose load, the GLP-1 response upon solid mixed meal in diabetic patients and

Table 3 Linear regression analyses of incretins with fasting triglycerides, triglyceride responses and ALT $(n=182)$.

\begin{tabular}{|c|c|c|c|}
\hline & \multicolumn{3}{|c|}{ Standardized regression coefficient $(95 \% \mathrm{Cl})$} \\
\hline & Fasting triglycerides & Triglycerides-tAUC & ALT \\
\hline \multicolumn{4}{|c|}{ Fasting GLP-1 } \\
\hline Model 1 & $0.02(-0.13$ to 0.17$)$ & $-0.03(-0.19$ to 0.14$)$ & $0.13(-0.01$ to 0.28$)$ \\
\hline Model 2 & $-0.11(-0.26$ to 0.05$)$ & $-0.13(-0.30$ to 0.04$)$ & $-0.01(-0.16$ to 0.14$)$ \\
\hline Model 3 & $-0.09(-0.24$ to 0.05$)$ & $-0.11(-0.27$ to 0.06$)$ & $-0.01(-0.15$ to 0.14$)$ \\
\hline \multicolumn{4}{|c|}{ Fasting GIP } \\
\hline Model 1 & $0.17(0.03 \text { to } 0.31)^{\star}$ & $0.18(0.02 \text { to } 0.33)^{\star}$ & $0.25(0.11 \text { to } 0.39)^{*}$ \\
\hline Model 2 & $0.11(-0.04$ to 0.25$)$ & $0.14(-0.02$ to 0.30$)$ & $0.17(0.03 \text { to } 0.30)^{*}$ \\
\hline Model 3 & $0.13(0.00 \text { to } 0.27)^{*}$ & $0.17(0.01 \text { to } 0.32)^{*}$ & $0.15(0.02 \text { to } 0.29)^{*}$ \\
\hline \multicolumn{4}{|c|}{ Post oral glucose GLP-1-tAUC } \\
\hline Model 1 & $-0.08(-0.23$ to 0.07$)$ & $-0.07(-0.23$ to 0.09$)$ & $0.01(-0.14$ to 0.15$)$ \\
\hline Model 2 & $-0.15(-0.31 \text { to } 0.00)^{*}$ & $-0.15(-0.31$ to 0.01$)$ & $-0.10(-0.23$ to 0.04$)$ \\
\hline Model 3 & $-0.11(-0.25$ to 0.03$)$ & $-0.11(-0.26$ to 0.05$)$ & $-0.08(-0.21$ to 0.05$)$ \\
\hline \multicolumn{4}{|c|}{ Post oral glucose GIP-tAUC } \\
\hline Model 1 & $0.20(0.05 \text { to } 0.36)^{\star}$ & $0.25(0.09 \text { to } 0.41)^{\star}$ & $0.14(-0.01$ to 0.28$)$ \\
\hline Model 2 & $0.14(-0.02$ to 0.30$)$ & $0.17(0.002 \text { to } 0.34)^{*}$ & $0.02(-0.13$ to 0.16$)$ \\
\hline Model 3 & $0.15(0.004 \text { to } 0.30)^{*}$ & $0.17(0.01 \text { to } 0.33)^{*}$ & $0.01(-0.13$ to 0.14$)$ \\
\hline \multicolumn{4}{|c|}{ Post mixed meal GLP-1-tAUC } \\
\hline Model 1 & $-0.04(-0.20$ to 0.12$)$ & $-0.001(-0.17$ to 0.17$)$ & $-0.002(-0.16$ to 0.16$)$ \\
\hline Model 2 & $-0.08(-0.24$ to 0.07$)$ & $-0.04(-0.21$ to 0.12$)$ & $-0.05(-0.21$ to 0.10$)$ \\
\hline Model 3 & $-0.02(-0.17$ to 0.12$)$ & $-0.01(-0.17$ to 0.15$)$ & $-0.03(-0.18$ to 0.11$)$ \\
\hline \multicolumn{4}{|c|}{ Post mixed meal GIP-tAUC } \\
\hline Model 1 & $0.05(-0.12$ to 0.22$)$ & $0.15(-0.04$ to 0.33$)$ & $0.15(-0.02$ to 0.32$)$ \\
\hline Model 2 & $-0.04(-0.22$ to 0.13$)$ & $0.06(-0.12$ to 0.25$)$ & $0.04(-0.13$ to 0.21$)$ \\
\hline Model 3 & $0.01(-0.16$ to 0.17$)$ & $0.11(-0.08$ to 0.29$)$ & $0.03(-0.13$ to 0.19$)$ \\
\hline
\end{tabular}

ALT, alanine aminotransferase; tAUC, total area under the curve; OGIS, oral glucose insulin sensitivity index; triglycerides-tAUC, tAUC following mixed meal test (for fasting and post mixed meal incretins) or oral glucose (for post oral glucose incretins). ${ }^{*} P<0.05$. Model 1 , including age and sex; Model 2 , including age, sex and glucose tolerance state; Model 3, including age, sex, glucose tolerance state, OGIS and glucagon (fasting, post oral glucose and post mixed meal glucagon for respective GLP-1 and GIP values). 
especially the potential relevance of a diminished iAUC warrants further attention in future studies. Further, the present data indicate that the consequences of altered GLP-1 and GIP secretion may be more comprehensive than yet understood, including effects on lipid metabolism and liver fat.

\section{Conclusions}

This study confirms earlier findings of a generally preserved GLP-1 secretion in type 2 diabetes and shows exaggerated GIP secretion in this population. The associations of GLP-1 and GIP secretion with (postprandial) triglycerides and ALT suggest that these hormones may reflect risk for dyslipidemia and liver fat accumulation in an opposite way.

\section{Supplementary data}

This is linked to the online version of the paper at http://dx.doi.org/ 10.1530/EJE-13-0487.

\section{Declaration of interest}

J M Rijkelijkhuizen, J J Holst, T Teerlink, P G Scheffer, E M W Eekhoff, A Gastaldelli, A Mari, L M 't Hart and G Nijpels have nothing to declare. M Alssema is currently employed by Unilever Research and Development. J M Dekker received an unrestricted investigatorinitiated grant of Merck \& Co., Inc.

\section{Funding}

This study was financially supported by an unrestricted investigatorinitiated grant of Merck \& Co., Inc.

\section{Acknowledgements}

The authors thank Jolanda Bosman and research assistants of the Diabetes Research Center in Hoorn for performing the study. They are grateful for excellent technical assistance from Sofie Pilgaard Olesen, Copenhagen University.

\section{References}

1 Nauck M, Stockmann F, Ebert R \& Creutzfeldt W. Reduced incretin effect in type 2 (non-insulin-dependent) diabetes. Diabetologia 198629 46-52. (doi:10.1007/BF02427280)

2 Vilsboll T, Krarup T, Madsbad S \& Holst JJ. Defective amplification of the late phase insulin response to glucose by GIP in obese type II diabetic patients. Diabetologia 200245 1111-1119. (doi:10.1007/s00125-002-0878-6)

3 Nauck MA, Heimesaat MM, Orskov C, Holst JJ, Ebert R \& Creutzfeldt W. Preserved incretin activity of glucagon-like peptide 1 [7-36 amide] but not of synthetic human gastric inhibitory polypeptide in patients with type-2 diabetes mellitus. Journal of Clinical Investigation 199391 301-307. (doi:10.1172/JCI11 6186)

4 Zander M, Madsbad S, Madsen JL \& Holst JJ. Effect of 6-week course of glucagon-like peptide 1 on glycaemic control, insulin sensitivity, and $\beta$-cell function in type 2 diabetes: a parallel-group study. Lancet 2002359 824-830. (doi:10.1016/S0140-6736(02) 07952-7)
5 Calanna S, Christensen M, Holst JJ, Laferrere B, Gluud LL, Vilsboll T \& Knop FK. Secretion of glucagon-like peptide-1 in patients with type 2 diabetes mellitus: systematic review and metaanalyses of clinical studies. Diabetologia 201356 965-972. (doi:10.1007/s00125-013-2841-0)

6 Nauck MA, Vardarli I, Deacon CF, Holst JJ \& Meier JJ. Secretion of glucagon-like peptide-1 (GLP-1) in type 2 diabetes: what is up, what is down? Diabetologia 201154 10-18. (doi:10.1007/ s00125-010-1896-4)

7 Vollmer K, Holst JJ, Baller B, Ellrichmann M, Nauck MA, Schmidt WE \& Meier JJ. Predictors of incretin concentrations in subjects with normal, impaired, and diabetic glucose tolerance. Diabetes 200857 678-687. (doi:10.2337/db07-1124)

8 Toft-Nielsen MB, Damholt MB, Madsbad S, Hilsted LM, Hughes TE, Michelsen BK \& Holst JJ. Determinants of the impaired secretion of glucagon-like peptide-1 in type 2 diabetic patients. Journal of Clinical Endocrinology and Metabolism 200186 3717-3723. (doi:10.1210/jc.86.8.3717)

9 Jones IR, Owens DR, Luzio S, Williams S \& Hayes TM. The glucose dependent insulinotropic polypeptide response to oral glucose and mixed meals is increased in patients with type 2 (non-insulindependent) diabetes mellitus. Diabetologia 198932 668-677. (doi:10.1007/BF00274255)

10 Lee S, Yabe D, Nohtomi K, Takada M, Morita R, Seino Y \& Hirano T. Intact glucagon-like peptide- 1 levels are not decreased in Japanese patients with type 2 diabetes. Endocrine Journal 201057 119-126. (doi:10.1507/endocrj.K09E-269)

11 Vilsboll T, Krarup T, Sonne J, Madsbad S, Volund A, Juul AG \& Holst JJ. Incretin secretion in relation to meal size and body weight in healthy subjects and people with type 1 and type 2 diabetes mellitus. Journal of Clinical Endocrinology and Metabolism $2003 \mathbf{8 8}$ 2706-2713. (doi:10.1210/jc.2002-021873)

12 Theodorakis MJ, Carlson O, Michopoulos S, Doyle ME, Juhaszova M, Petraki K \& Egan JM. Human duodenal enteroendocrine cells: source of both incretin peptides, GLP-1 and GIP. American Journal of Physiology. Endocrinology and Metabolism 2006 290 E550-E559. (doi:10.1152/ajpendo.00326.2004)

13 Ryskjaer J, Deacon CF, Carr RD, Krarup T, Madsbad S, Holst J \& Vilsboll T. Plasma dipeptidyl peptidase-IV activity in patients with type-2 diabetes mellitus correlates positively with HbAlc levels, but is not acutely affected by food intake. European Journal of Endocrinology 2006155 485-493. (doi:10.1530/eje.1.02221)

14 Forst T, Weber MM \& Pfutzner A. Cardiovascular benefits of GLP-1-based herapies in patients with diabetes mellitus type 2: effects on endothelial and vascular dysfunction beyond glycemic control. Experimental Diabetes Research 20122012635472. (doi:10.1155/2012/635472)

15 Klonoff DC, Buse JB, Nielsen LL, Guan X, Bowlus CL, Holcombe JH, Wintle ME \& Maggs DG. Exenatide effects on diabetes, obesity, cardiovascular risk factors and hepatic biomarkers in patients with type 2 diabetes treated for at least 3 years. Current Medical Research and Opinion 200824 275-286. (doi:10.1185/0300 79908X253870)

16 Taskinen MR. Diabetic dyslipidaemia: from basic research to clinical practice. Diabetologia 200346 733-749. (doi:10.1007/ s00125-003-1111-y)

17 Sarwar N, Sandhu MS, Ricketts SL, Butterworth AS, Di Angelantonio E, Boekholdt SM, Ouwehand W, Watkins H, Samani NJ, Saleheen D et al. Triglyceride-mediated pathways and coronary disease: collaborative analysis of 101 studies. Lancet 2010 375 1634-1639. (doi:10.1016/S0140-6736(10)60545-4)

18 Meier JJ, Gethmann A, Gotze O, Gallwitz B, Holst JJ, Schmidt WE \& Nauck MA. Glucagon-like peptide 1 abolishes the postprandial rise in triglyceride concentrations and lowers levels of non-esterified fatty acids in humans. Diabetologia $2006 \quad \mathbf{4 9} \quad 452-458$. (doi:10.1007/s00125-005-0126-y)

19 Courreges JP, Vilsboll T, Zdravkovic M, Le Thi T, Krarup T, Schmitz O, Verhoeven R, Buganova I \& Madsbad S. Beneficial effects of once-daily liraglutide, a human glucagon-like peptide-1 
analogue, on cardiovascular risk biomarkers in patients with type 2 diabetes. Diabetic Medicine 200825 1129-1131. (doi:10.1111/ j.1464-5491.2008.02484.x)

20 Astrup A, Carraro R, Finer N, Harper A, Kunesova M, Lean ME, Niskanen L, Rasmussen MF, Rissanen A, Rossner S et al. Safety, tolerability and sustained weight loss over 2 years with the oncedaily human GLP-1 analog, liraglutide. International Journal of Obesity 201236 843-854. (doi:10.1038/ijo.2011.158)

21 Ding X, Saxena NK, Lin S, Gupta NA \& Anania FA. Exendin-4, a glucagon-like protein-1 (GLP-1) receptor agonist, reverses hepatic steatosis in ob/ob mice. Hepatology 200643 173-181. (doi:10.1002/hep.21006)

22 Flatt PR. Dorothy Hodgkin Lecture 2008. Gastric inhibitory polypeptide (GIP) revisited: a new therapeutic target for obesitydiabetes? Diabetic Medicine 200825 759-764. (doi:10.1111/ j.1464-5491.2008.02455.x)

23 McClean PL, Irwin N, Cassidy RS, Holst JJ, Gault VA \& Flatt PR. GIP receptor antagonism reverses obesity, insulin resistance, and associated metabolic disturbances induced in mice by prolonged consumption of high-fat diet. American Journal of Physiology. Endocrinology and Metabolism 2007293 E1746-E1755. (doi:10.1152/ajpendo.00460.2007)

24 Clements RH, Gonzalez QH, Long CI, Wittert G \& Laws HL. Hormonal changes after Roux-en Y gastric bypass for morbid obesity and the control of type-II diabetes mellitus. American Surgeon 200470 1-4.

25 Rijkelijkhuizen JM, Girman CJ, Mari A, Alssema M, Rhodes T, Nijpels G, Kostense PJ, Stein PP, Eekhoff EM, Heine RJ et al. Classical and model-based estimates of $\beta$-cell function during a mixed meal vs. an OGTT in a population-based cohort. Diabetes Research and Clinical Practice 200983 280-288. (doi:10.1016/ j.diabres.2008.11.017)

26 World Health Organization. Definition and diagnosis of diabetes mellitus and intermediate hyperglycemia. Report of a WHO/IDF consultation 2006.

27 Nauck MA, El-Ouaghlidi A, Gabrys B, Hucking K, Holst JJ, Deacon CF, Gallwitz B, Schmidt WE \& Meier JJ. Secretion of incretin hormones (GIP and GLP-1) and incretin effect after oral glucose in first-degree relatives of patients with type 2 diabetes. Regulatory Peptides 2004122 209-217. (doi:10.1016/j.regpep. 2004.06.020)

28 Deacon CF, Nauck MA, Meier J, Hucking K \& Holst JJ. Degradation of endogenous and exogenous gastric inhibitory polypeptide in healthy and in type 2 diabetic subjects as revealed using a new assay for the intact peptide. Journal of Clinical Endocrinology and Metabolism 200085 3575-3581. (doi:10.1210/jc.85.10.3575)

29 Mari A, Pacini G, Murphy E, Ludvik B \& Nolan JJ. A model-based method for assessing insulin sensitivity from the oral glucose tolerance test. Diabetes Care 200124 539-548. (doi:10.2337/ diacare.24.3.539)

30 Twisk J. Applied longitudinal data analysis for epidemiology: a practical guide. Cambridge University Press, 2006.

31 Cho YM \& Kieffer TJ. New aspects of an old drug: metformin as a glucagon-like peptide 1 (GLP-1) enhancer and sensitiser. Diabetologia 201154 219-222. (doi:10.1007/s00125-0101986-3)

32 Faerch K, Vaag A, Holst JJ, Glumer C, Pedersen O \& BorchJohnsen K. Impaired fasting glycaemia vs impaired glucose tolerance: similar impairment of pancreatic $\alpha$ and $\beta$ cell function but differential roles of incretin hormones and insulin action. Diabetologia $2008 \quad 51 \quad 853-861$. (doi:10.1007/s00125-0080951-x)

33 Laakso M, Zilinskaite J, Hansen T, Boesgaard TW, Vanttinen M, Stancakova A, Jansson PA, Pellme F, Holst JJ, Kuulasmaa T et al. Insulin sensitivity, insulin release and glucagon-like peptide-1 levels in persons with impaired fasting glucose and/or impaired glucose tolerance in the EUGENE2 study. Diabetologia $2008 \mathbf{5 1}$ 502-511. (doi:10.1007/s00125-007-0899-2)
34 Deacon CF. What do we know about the secretion and degradation of incretin hormones? Regulatory Peptides 2005128 117-124. (doi:10.1016/j.regpep.2004.06.007)

35 Ranganath LR, Beety JM, Morgan LM, Wright JW, Howland R \& Marks V. Attenuated GLP-1 secretion in obesity: cause or consequence? Gut 199638 916-919. (doi:10.1136/gut.38. 6.916)

36 Dube PE \& Brubaker PL. Nutrient, neural and endocrine control of glucagon-like peptide secretion. Hormone and Metabolic Research 200436 755-760. (doi:10.1055/s-2004-826159)

37 Lindgren O, Carr RD, Deacon CF, Holst JJ, Pacini G, Mari A \& Ahren B. Incretin hormone and insulin responses to oral versus intravenous lipid administration in humans. Journal of Clinical Endocrinology and Metabolism 201196 2519-2524. (doi:10.1210/jc.2011-0266)

38 Horowitz M, Wishart JM, Jones KL \& Hebbard GS. Gastric emptying in diabetes: an overview. Diabetic Medicine 199613 S16-S22.

39 Phillips WT, Schwartz JG \& McMahan CA. Rapid gastric emptying of an oral glucose solution in type 2 diabetic patients. Journal of Nuclear Medicine 199233 1496-1500.

40 Ahren B, Larsson H \& Holst JJ. Reduced gastric inhibitory polypeptide but normal glucagon-like peptide 1 response to oral glucose in postmenopausal women with impaired glucose tolerance. European Journal of Endocrinology $1997 \quad 137 \quad 127-131$. (doi:10.1530/eje.0.1370127)

41 Muscelli E, Mari A, Casolaro A, Camastra S, Seghieri G, Gastaldelli A, Holst JJ \& Ferrannini E. Separate impact of obesity and glucose tolerance on the incretin effect in normal subjects and type 2 diabetic patients. Diabetes 200857 1340-1348. (doi:10.2337/db07-1315)

42 Hansen KB, Vilsboll T, Bagger JI, Holst JJ \& Knop FK. Impaired incretin-induced amplification of insulin secretion after glucose homeostatic dysregulation in healthy subjects. Journal of Clinical Endocrinology and Metabolism 201297 1363-1370. (doi:10.1210/jc.2011-2594)

43 Holst JJ, Knop FK, Vilsboll T, Krarup T \& Madsbad S. Loss of incretin effect is a specific, important, and early characteristic of type 2 diabetes. Diabetes Care 201134 (Suppl 2) S251-S257. (doi:10.2337/dc11-s227)

44 Vilsboll T, Krarup T, Deacon CF, Madsbad S \& Holst JJ. Reduced postprandial concentrations of intact biologically active glucagon-like peptide 1 in type 2 diabetic patients. Diabetes 2001 50 609-613. (doi:10.2337/diabetes.50.3.609)

45 Holst JJ, Christensen M, Lund A, de Heer J, Svendsen B, Kielgast U $\&$ Knop FK. Regulation of glucagon secretion by incretins. Diabetes, Obesity and Metabolism 201113 (Suppl 1) 89-94. (doi:10.1111/ j.1463-1326.2011.01452.x)

46 Hansen L, Hartmann B, Mineo H \& Holst JJ. Glucagon-like peptide-1 secretion is influenced by perfusate glucose concentration and by a feedback mechanism involving somatostatin in isolated perfused porcine ileum. Regulatory Peptides 2004118 11-18. (doi:10.1016/ j.regpep.2003.10.021)

47 Brons C, Jensen CB, Storgaard H, Hiscock NJ, White A, Appel JS, Jacobsen S, Nilsson E, Larsen CM, Astrup A et al. Impact of short-term high-fat feeding on glucose and insulin metabolism in young healthy men. Journal of Physiology 2009587 2387-2397. (doi:10.1113/jphysiol.2009.169078)

48 Irwin N \& Flatt PR. Evidence for beneficial effects of compromised gastric inhibitory polypeptide action in obesity-related diabetes and possible therapeutic implications. Diabetologia $2009 \mathbf{5 2}$ 1724-1731. (doi:10.1007/s00125-009-1422-8)

Received 7 January 2013

Revised version received 28 June 2013

Accepted 17 July 2013 